\title{
The Implications of Fabrication and Cast-to-Cast Variability on Thermal Aging in the Creep Range for AISI Type 316H Stainless Steel Components

\begin{abstract}
A.D. WARREN, A. MARTINEZ-UBEDA, I. GRIFFITHS, and P.E.J. FLEWITT
Life prediction is critical for safe operation of plant within the creep regime. This study investigates the influence differences in specific composition and fabrication routes have on creep degradation for components with compositions within the design specification. Four ex-service AISI $316 \mathrm{H}$ austenitic stainless steel components exhibiting different manufacturing techniques and a range of compositions were used in the study. The boiler header component was found to contain localized chromium-rich regions arising from the original cast microstructure which result in a wide range of phases and show enhanced creep cavitation. Chi-phase precipitates contribute a significant role in creep damage accumulation via phosphorus segregation to the chi-austenite inter-phase boundaries. Tubular components with a homogenous microstructure and similar composition to the header showed limited secondary phase evolution. In one tubular specimen, creep cavitation was linked to phosphorus segregation at $\mathrm{M}_{23} \mathrm{C}_{6}$-austenite inter-phase boundaries. The remaining two tubular components, with a higher (but within specification) silicon content, showed homogeneous microstructures with limited creep cavitation and no phosphorus segregation was observed.
\end{abstract}

https://doi.org/10.1007/s11661-018-4991-7

(C) The Author(s) 2018

\section{INTRODUCTION}

AUsTENITIC stainless steels such as the Type 316 series are frequently used to manufacture high-temperature plant components, since they possess high strength and corrosion resistance. ${ }^{[1,2]}$ As such, these steels are frequently fabricated into components that have a wide range of shapes - from thin-walled pipes to large cast components and beyond. The influence of a range of fabrication affects such as welding ${ }^{[3,4]}$ and cold work ${ }^{[5]}$ on in service creep has been the subject of a large number of previous studies. These studies have considered factors such as the introduction of residual stresses, ${ }^{[6,7]}$ changes in grain structure, ${ }^{[8]}$ enhanced diffusion kinetics, ${ }^{[5]}$ and secondary phase evolution. ${ }^{[8-10]}$ Many studies make the assumption that these materials have a uniform microstructure and that findings can be

A.D. WARREN and A. MARTINEZ-UBEDA are with the Interface Analysis Centre, H.H. Wills Physics Laboratory, University of Bristol, Bristol, BS8 1FD, UK. Contact e-mail: xander.warren@bristol.ac.uk I. GRIFFITHS is with the Department of Materials, University of Oxford, Parks Rd, Oxford, OX1 3PH, UK. P.E.J. FLEWITT is with the Interface Analysis Centre, H.H. Wills Physics Laboratory, University of Bristol and also with the School of Physics, H.H. Wills Physics Laboratory, University of Bristol, Bristol, BS8 1FD, UK.

Manuscript submitted January 9, 2018.

Article published online November 27, 2018 applied to other AISI Type 316 steel components regardless of fabrication route and differences in the specific composition (within the design specification).

A range of manufacturing routes for austenitic steel exist, although the process used for the AISI Type $316 \mathrm{H}$ steels analyzed in this study is a primary ferrite casting process. $^{[11-14]}$ During primary ferrite solidification, $\delta$-ferrite is formed initially during casting. Nickel, manganese, and molybdenum segregate from the $\delta$-ferrite to the melt, while chromium is retained in the $\delta$-ferrite grains. This local enrichment leads to the formation of austenite on the $\delta$-ferrite dendrites ${ }^{[12]}$ and diffusional segregation of elements continues even after solidification. ${ }^{[1-13]}$ In certain places, the concentration of ferrite-stabilizing elements present in the $\delta$-ferrite dendrites is insufficient to stabilize it at lower temperatures; instead, it is converted to Widmanstätten austenite during the cooling stage. ${ }^{[12]}$ As the solidification is rapid (i.e., non-equilibrium), a portion of $\delta$-ferrite is retained at room temperature as there is insufficient time for extensive diffusion of elements to occur. ${ }^{[15-18]}$ Also imperfections in the casting and mixing processes can lead to inhomogeneities in the distribution of alloying elements. The formation of austenite disrupts the growth of the $\delta$-ferrite dendrites, leading to a mixed microstructure. ${ }^{[12]}$ At room temperature, the residual $\delta$-ferrite is commonly observed at interdendritic regions. ${ }^{[11]}$ These interdendritic regions may be 
preserved in the final component, or they maybe be homogenized during subsequent fabrication.

Low-volume fractions of residual ferrite can prove beneficial to the properties of austenitic steels under certain circumstances. For example, it can prevent heat shrinkage in continuously cast material, increase the strength of the material, and inhibit the formation of longitudinal cracks. ${ }^{[15,17]}$ Higher volume fractions of ferrite can decrease the corrosion resistance of the material through sensitization, cause a reduction in the hot workability of the material, and can facilitate hot cracking. ${ }^{[3,4,12,15,17,19,20]}$ Under certain conditions, the ferrite transforms into a range of secondary phases, often with deleterious effects on the mechanical and chemical properties of the material. These phases include chi phase ${ }^{[21]}$ and $G$ phase. ${ }^{[2]}$

Chi phase is a body-centered cubic (BCC) intermetallic phase $\left(a=0.881\right.$ to $\left.0.895 \mathrm{~nm}^{[22]}\right)$ with a composition range of $(\mathrm{Fe} / \mathrm{Ni})_{36} \mathrm{Cr}_{12} \mathrm{Mo}_{10}$ to $(\mathrm{Fe} / \mathrm{Ni})_{36} \mathrm{Cr}_{12}$ $\mathrm{Mo}_{3} \mathrm{Ti}_{7 .}{ }^{[21-25]} \mathrm{Chi}$ phase has been observed to nucleate and grow preferentially into $(\alpha$ and $\delta$ ) ferrite precipitates $^{[21,26-29]}$ and has been observed in association with $\mathrm{M}_{23} \mathrm{C}_{6}$ carbide precipitates. ${ }^{[30]} \mathrm{Chi}$ phase has a deleterious influence on corrosion resistance and room temperature fracture toughness ${ }^{[22,29]}$ but has been observed to not influence either creep deformation or damage behavior. ${ }^{[24,31]} \mathrm{G}$ phase is a face-centered cubic (FCC) intermetallic phase $\left(a=1.115\right.$ to $\left.1.120 \mathrm{~nm}^{[22]}\right)$ with a nominal composition observed in austenitic stainless steels of $(\mathrm{Ni} / \mathrm{Fe} / \mathrm{Cr} / \mathrm{Mo})_{16}(\mathrm{Nb} / \mathrm{Ti})_{6} \mathrm{Si}_{6} \cdot{ }^{[22,32]}$ In the temperature range of $250{ }^{\circ} \mathrm{C}$ to $500{ }^{\circ} \mathrm{C},{ }^{[22,33,34]} \mathrm{G}$ phase nucleates at, and consumes, $(\alpha$ and $\delta$ ) ferrite precipitates $^{[35-38]}$ in austenitic steels. Higher aging temperatures are associated with $G$ phase forming from austenite. ${ }^{[35]}$ $\mathrm{G}$ phase has been found to cause embrittlement and promote intergranular fracture. ${ }^{[38,39]}$

In this study, we assess the role differences in composition and fabrication play on thermal aging, and its implications for creep performance. The effect of fabrication is assessed by comparing four steel components of similar compositions, but significantly different fabrication methods. One of the fabrication routes has left the interdendritic regions intact leading to a significant heterogeneity in the microstructure, while the other is fully homogenized. The impact of cast-to-cast composition variation is assessed through three homogenized components, each with differing compositions which fall within the design specification. The implications of these differences on the thermal evolution of the microstructure and the corresponding influence on creep behavior are discussed, in particular (i) the influence of the remnant local interdentritic regions on subsequent precipitation and (ii) the distribution of $\mathrm{P}$ arising from the presence of a specific phase.

\section{EXPERIMENTAL}

The specimens studied in this work were all extracted from AISI Type $316 \mathrm{H}$ austenitic stainless steel components. The first specimen was removed from a boiler header which experienced 65,000 -hour operation in the temperature range of $490{ }^{\circ} \mathrm{C}$ to $530{ }^{\circ} \mathrm{C}$ and pressure range of 2000 to $2500 \Psi$, in a complex multi-axial stress state (compounded by a nearby weldment). This was followed by post-service laboratory thermal aging (unloaded) for 22,100 hours at $550{ }^{\circ} \mathrm{C}$ to investigate the contribution from further thermal aging. The header has creep cavities present and failed through creep cracking. The other specimens are ex-service tube bifurcations, fabricated by bending a parent tube through an angle of $150 \mathrm{deg}$, and cutting the bent region to generate an oval opening. A two-pass TIG weld (AISI Type $316 \mathrm{H}$ filler) was used to attach a transition stub to the cut region. Of these highly worked components, all were aged in service at $505^{\circ} \mathrm{C}$. Specimen A was aged for 160,000 hours and had creep cracks, specimen B for 145,000 hours, and specimen $\mathrm{C}$ for 300,000 hours, all with the same pressure range as the header. The tubes are in a complex multi-axial stress state, with the hoop-stress dominating. Compositions for all materials in wt pet are given in Table I.

The microstructures of these two types of specimen have been significantly influenced by the fabrication processes adopted. The thick-walled header shows regions of finer grain size and chromium enrichment, where interdendritic regions from the original cast have not been fully homogenized. The parent metal of the thin-walled bifurcation is significantly more homogenous due to the more severe deformation of the pipe-stock applied during the fabrication process of the component. Figures 1(a) and (b) show optical micrographs of the specimens, illustrating the difference in microstructure.

Specimens were prepared using consecutive polishing with silicon carbide papers and diamond pastes to obtain a $1 / 4 \mu \mathrm{m}$ surface finish. For electron backscatter diffraction (EBSD) imaging, a further vibratory polish with $0.1 \mu \mathrm{m}$ colloidal silica was used to improve pattern quality. EBSD analysis was performed with the

Table I. Composition of the Ex-service Type 316H Austenitic Stainless Steel Header and the Three Ex-service Type 316 Austenitic Stainless Steel Bifurcation Tubing (Weight Percent)

\begin{tabular}{lcccccccccccc}
\hline Sample & $\mathrm{C}$ & $\mathrm{Si}$ & $\mathrm{Mn}$ & $\mathrm{P}$ & $\mathrm{S}$ & $\mathrm{Cr}$ & $\mathrm{Mo}$ & $\mathrm{Ni}$ & $\mathrm{B}$ & $\mathrm{Co}$ & $\mathrm{Cu}$ & $\mathrm{Fe}$ \\
\hline Ex-service boiler header & 0.06 & 0.40 & 1.98 & 0.02 & 0.01 & 17.17 & 2.19 & 11.83 & 0.01 & 0.10 & - & 66.23 \\
Ex-service bifuraction A & 0.05 & 0.45 & 1.43 & 0.02 & 0.01 & 16.21 & 2.43 & 11.48 & - & 0.05 & 0.11 & bal. \\
Ex-service bifuraction B & 0.06 & 0.64 & 1.71 & 0.04 & 0.01 & 15.80 & 2.14 & 13.59 & - & 0.02 & 0.05 & bal. \\
Ex-service bifuraction C & 0.05 & 0.59 & 1.19 & 0.03 & 0.01 & 16.49 & 2.04 & 14.07 & - & - & - & bal. \\
\hline
\end{tabular}

Values supplied by EDF Energy Ltd. following optical emission spectrometry (OES) analysis. Error on measurements not supplied. 


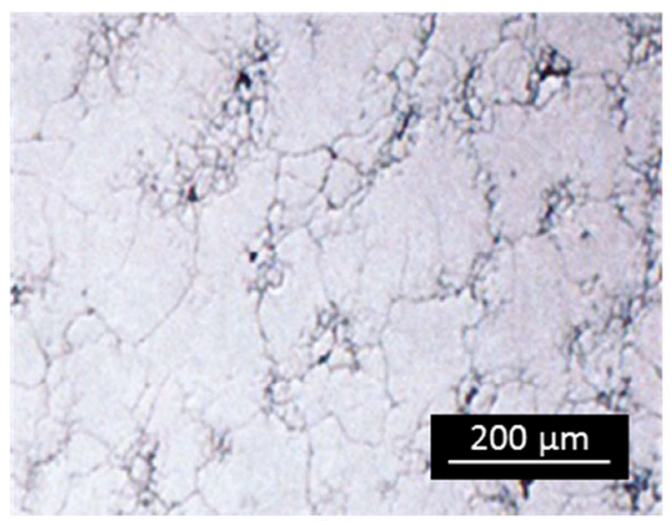

(a)

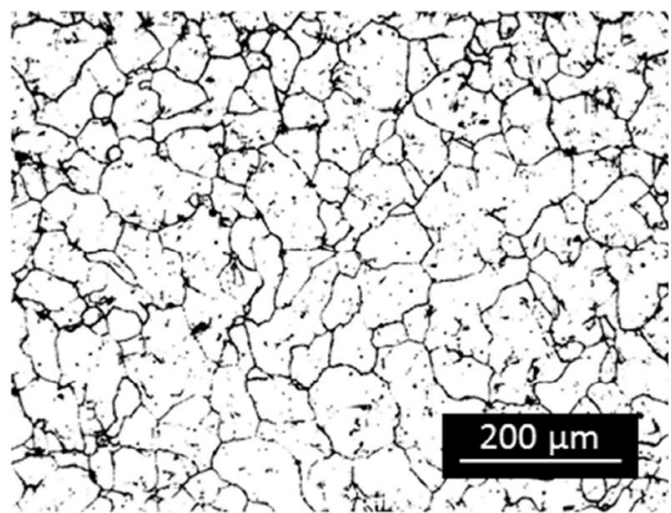

(b)

Fig. 1-Optical micrographs showing the influence of fabrication on the ex-service Type $316 \mathrm{H}$ components. $(a)$ The boiler header, showing the distribution of fine-grained, $\mathrm{Cr}$-rich, interdendritic regions. These regions contain a mix of phases, predominantly austenite, ferrite, and $\mathrm{M}_{23} \mathrm{C}_{6}$ carbide (reprinted with authors' permission from Ref. [40]). (b) The bifurcation tube A microstructure.

specimen inclined at 70 deg to the horizontal in a Zeiss SIGMA FEG-SEM, fitted with a DigiView 3 high-speed camera, and operating at $30 \mathrm{kV}$. Data were collected using orientation image mapping (OIM) software (Ametek, Utah, USA).

Thin foils for transmission electron analysis were prepared using ion-milling in a FEI Helios Nanolab 600i 'Dual beam' SEM/FIB workstation. Following extraction, a low-energy $5 \mathrm{kV}$ gallium ion mill was used to reduce surface damage. Transmission electron microscopy (TEM) and scanning transmission electron microscopy (STEM) analysis was performed using a JEOL-ARM 200F, operating at $200 \mathrm{kV}$. Energy dispersive X-ray spectroscopy (STEM-EDX) used a $100 \mathrm{~mm}^{2}$ Centurion detector and the data were analyzed using the NSS version 3.2 analysis software. For individual point measurements, a dwell of 30 seconds was used to acquire the composition data, while line scans used 5 -second dwells repeated 6 times with a dead time of 20 pct. Maps were collected with a $10 \mathrm{~nm}$ pixel size, with a dwell of $500 \mu$ s per pixel.

\section{RESULTS}

The microstructure of the boiler header and bifurcation tube A is significantly different, despite similar compositions. The header has two distinct sub regions - the bulk region has a mean austenite grain size of approximately $45 \mu \mathrm{m}$ dia. (maximum size $100 \mu \mathrm{m}$ dia.). The interdendritic regions by comparison had a mean austenite grain size of $10 \mu \mathrm{m}$ dia. (maximum size $20 \mu \mathrm{m}$ dia.), while the ferrite precipitates in this region had a mean size of $1.7 \mu \mathrm{m}$ dia. The austenite grains in bifurcation $\mathrm{A}, \mathrm{B}$, and $\mathrm{C}$ had a mean size of 23,56 , and $23 \mu \mathrm{m}$ dia., respectively. This is illustrated in the EBSD images in Figure 2.

The bifurcation phase distributions were studied using TEM. The TEM identification of the precipitate species in the header material has been extensively discussed in a previous paper. ${ }^{[40]}$ Figure 3(a) shows a cluster of secondary phase precipitates (including ferrite, $G$ phase, and $\mathrm{M}_{23} \mathrm{C}_{6}$ carbide, marked in Figure 3(b)) around a creep cavity in bifurcation A. Phase identification was achieved using electron diffraction, with patterns shown in Figures 3(c) through (e). This was combined with EDX mapping, Figure 3(f), to ensure compositions fell within the expected ranges and to highlight the distribution of phases. Figure 4 shows EDX maps from bifurcations B and C. Electron diffraction characterized the secondary phases present in bifurcation $\mathrm{A}$ as ferrite and $\mathrm{M}_{23} \mathrm{C}_{6}$, while bifurcation $\mathrm{C}$ contained ferrite, $\mathrm{G}$ phase, and $\mathrm{M}_{23} \mathrm{C}_{6}$ carbide. In both Figures 4(a) and (b), the $\mathrm{G}$ phase can be recognized by its higher silicon content, which is not present in the maps from bifurcation A. Although $\mathrm{G}$ phase is present in the header and in bifurcations $\mathrm{B}$ and $\mathrm{C}$; the $\mathrm{G}$ phase compositions recorded in both differ significantly, Table II. This is likely to be a consequence of a combination of effects relating to differences in both overall and local compositions.

These phase distributions between the two regions of the header and the three bifurcations are summarized in Table III, along with the volume fraction of the more common secondary phases. It should be noted that the volume fractions of ferrite and chi phase in the header interdendritic regions are convoluted due to the EBSD software's inability to distinguish the ferrite BCC structure from the chi-phase BCC microstructure, despite the difference in lattice parameter between the phases.

Composition microanalysis showed a difference in elemental segregation behavior between the boiler header, bifurcation $\mathrm{A}$, and bifurcations $\mathrm{B}$ and $\mathrm{C}$ :

- In the boiler header, the only elemental segregation noted at boundaries was phosphorus segregating $(0.65 \mathrm{wt} \mathrm{pct})$ to the austenite-chi inter-phase boundary, Figure 5(a). Phosphorus segregation at austenite-ferrite boundaries has been predicted. ${ }^{[40]}$ It should be noted that chromium depletion $(-1.96$ wt pct) has been observed surrounding chi precipitates affecting the local precipitation behavior. ${ }^{[40]}$

- Bifurcation A showed phosphorous segregation $(12 \mathrm{wt} \mathrm{pct})$ to the austenite- $\mathrm{M}_{23} \mathrm{C}_{6}$ inter-phase boundary, Figure 5(b). 


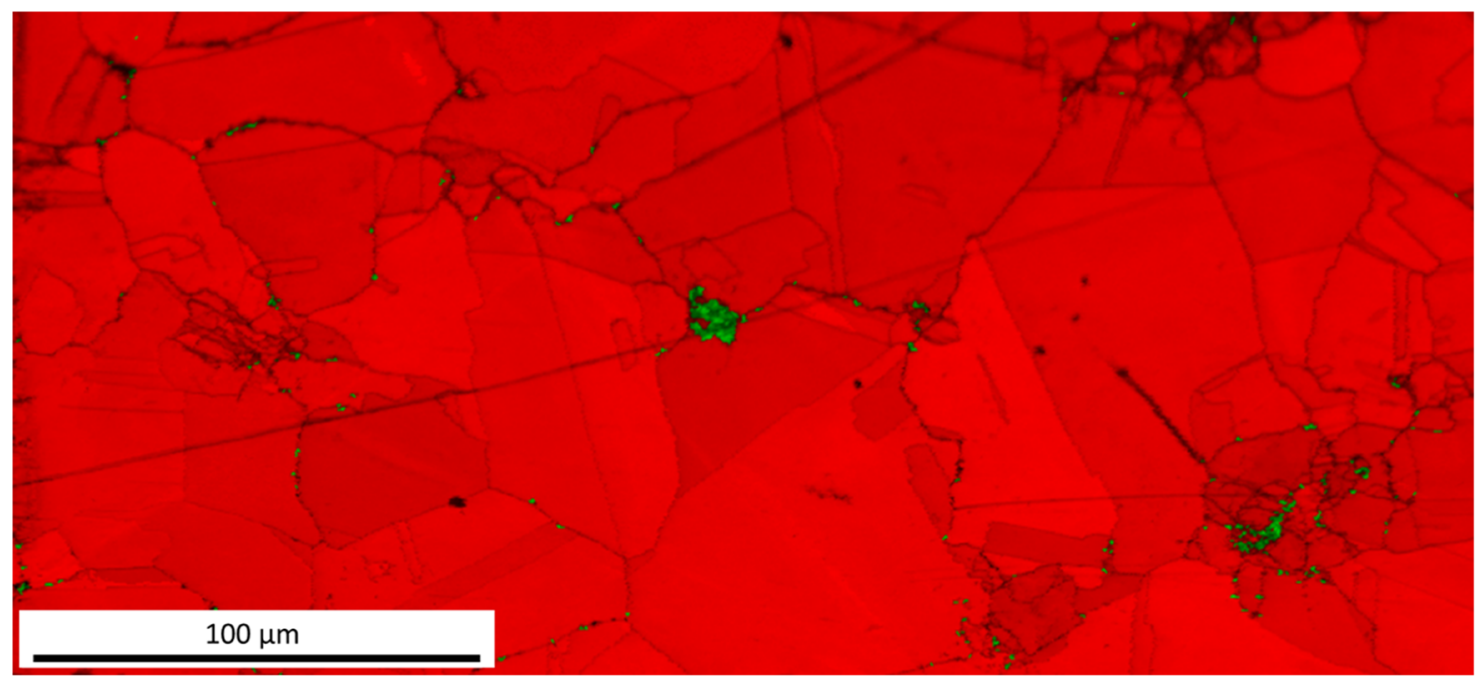

(a)

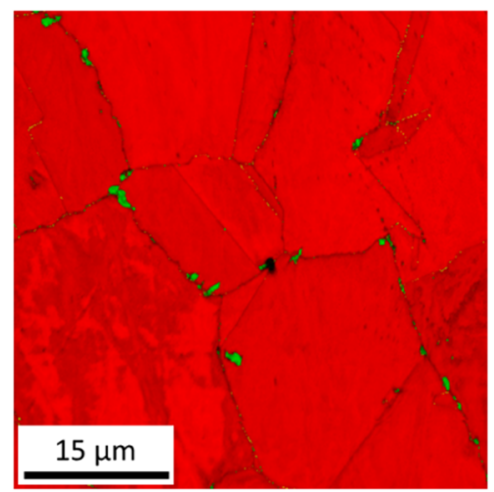

(b)

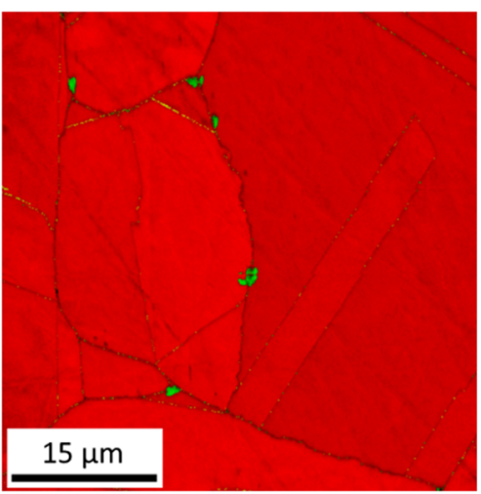

(c)

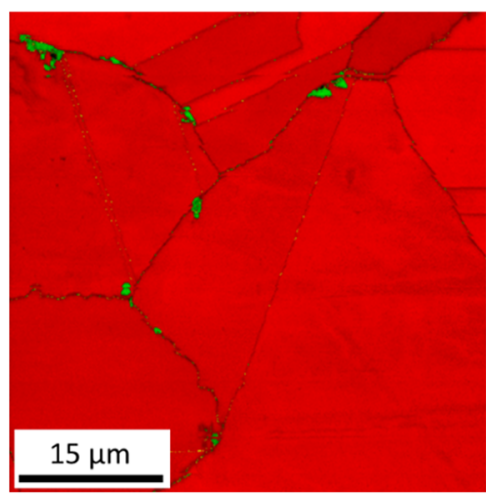

(d)

Fig. 2-EBSD phase maps showing the microstructure and phase distribution of the aged AISI Type 316H components. (a) The cast boiler header, showing the difference in grain size between the bulk austenite and the interdendritic regions, $(b)$ the microstructure of bifurcation A, $(c)$ the microstructure of bifurcation B, and $(d)$ the microstructure of bifurcation C. Austenite is red and ferrite is green on these maps (Color figure online).

- Bifurcations $\mathrm{B}$ and $\mathrm{C}$ do not show any elemental segregation to any phase or grain boundaries.

Atomic resolution imaging in the header showed periodic dislocations at the austenite-chi-phase interface, Figure 6(a), along with increased dislocation density around chi-phase precipitates under a range of tilt conditions, Figure 6(b). It is suggested that the greater lattice mismatch between the austenite and the chi phase than between austenite and ferrite (chi phase $a=0.795-0.845 \mathrm{~nm}^{[22]}$ vs austenite $a=0.358 \mathrm{~nm}^{[41]}$ and ferrite $a=0.285-0.289 \mathrm{~nm}$ ) may play a role in favoring segregation of phosphorus to chi phase over ferrite. High-resolution images of the austenite- $\mathrm{M}_{23} \mathrm{C}_{6}$ boundary in bifurcation A showed no comparable stored dislocations at the boundary, and no dislocation pile-ups were observed.

\section{DISCUSSION}

The four components studied in this work are all within design specification, and from a plant-design perspective would be expected to perform identically.
The production route for the thin-walled bifurcation had a homogenizing affect on the microstructure, breaking up the interdendritic regions generated during the casting. As can be seen by comparing the header with the bifurcations, the interdendritic regions, along with their differing grain size and composition, evolve very differently compared to the bulk material during prolonged thermal aging. Following aging, the interdendritic regions contain a much wider range of secondary phase precipitates than either the bulk header material or the homogenized bifurcation material. In addition to these fabrication affects, micro length scale variations in composition appear to play a significant role in both aging and behavior. This is reflected in the microstructural variations observed here and the fact that bifurcation A contained creep cracks while bifurcation $\mathrm{B}$ and $\mathrm{C}$ did not.

Yang and Busby developed a CALPHAD model specifically for evaluating the thermal aging of austenitic stainless steels. ${ }^{[42]}$ One of the examples presented is an AISI Type $316 \mathrm{H}$ which is compositionally similar to the boiler headers. Comparison between the predicted phases and those phases observed in the header interdendritic regions ${ }^{[40]}$ showed significant discrepancies. 


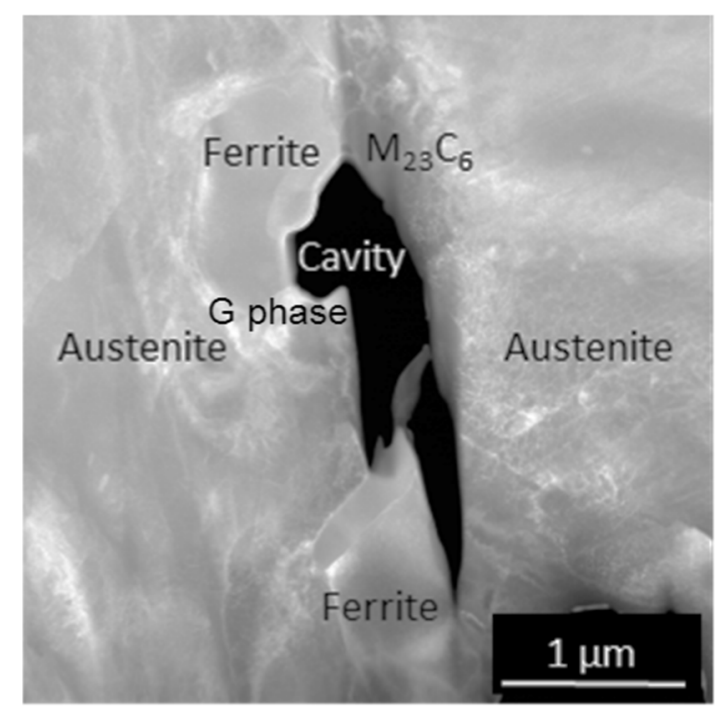

(a)

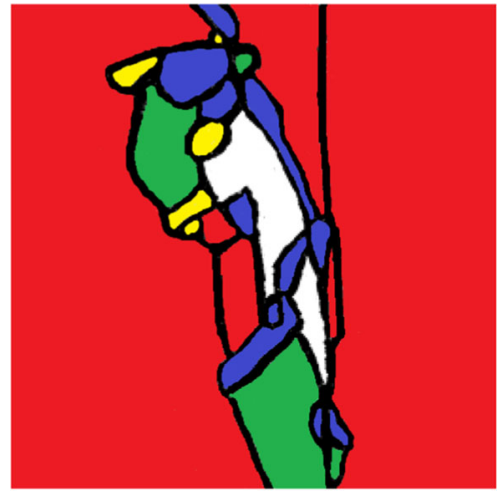

Austenite
Ferrite
$\mathrm{M}_{23} \mathrm{C}_{6}$
G phase

(b)

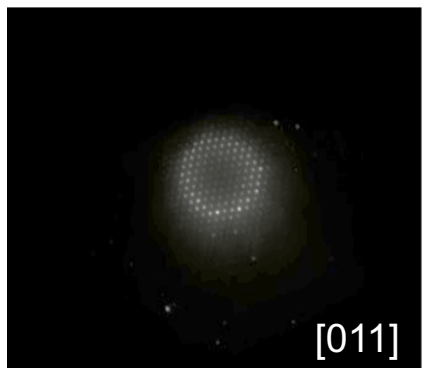

(c)

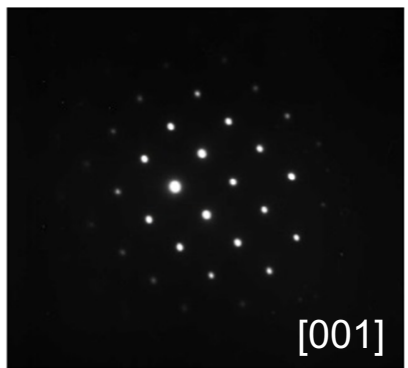

(d)
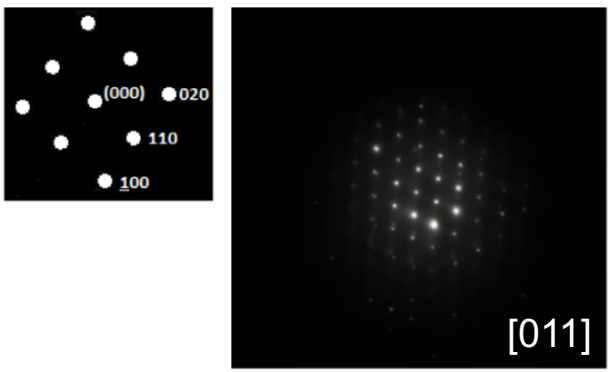

(e)

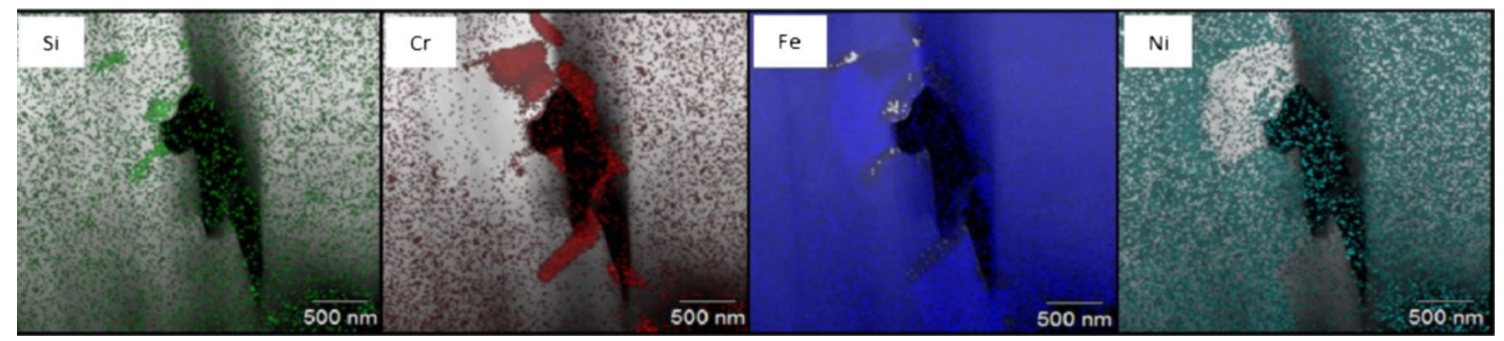

(f)

Fig. 3-Analysis of phases around a creep cavity in the ex-service bifurcation A. (a) STEM high-angle annular dark field (HAADF) image showing the distribution of phases, $(b)$ color coded phase key to show distribution of phase in (a), (c) diffraction pattern from $\mathrm{M}_{23} \mathrm{C}_{6}$, $(d)$ diffraction pattern for ferrite and indexed schematic, and $(e)$ diffraction pattern for austenite. $(f)$ STEM-EDX elemental maps for the region shown in a. All diffraction patterns were recorded at a constant camera length from the precipitates shown in (a).

This is presumably due to the localized, Cr-rich environment present in the interdendritic regions. However, Yang and Busby's predicted mix of austenite, sigmaphase, Laves-phase, $\mathrm{M}_{23} \mathrm{C}_{6}$ carbide, and an iron-rich ferrite $^{[42]}$ does not correlate well with the phases observed in the more homogenous microstructure of the bifurcation either. As with the header material, G phase is present in the bifurcation, which is not predicted by Yang and Busby under any aging conditions. ${ }^{[42]}$ This may reflect either an error with Yang and Busby's predictions or that G-phase formation occurs only in a very narrow compositional range such that the differences between header/bifurcation lead to the observed difference. Moreover, this compositional sensitivity could explain the significant differences in composition between the $\mathrm{G}$ phase present in the header and bifurcations $\mathrm{B}$ and $\mathrm{C}$, as well as its absence from bifurcation A.

The difference in the phases present in the header interdendritic regions compared to the bifurcations is significant. Chi phase has been observed to have deleterious effects on corrosion resistance due to sensitization and a reduction in fracture toughness. ${ }^{[22,29]}$ Given the observed pile-up of dislocations at 

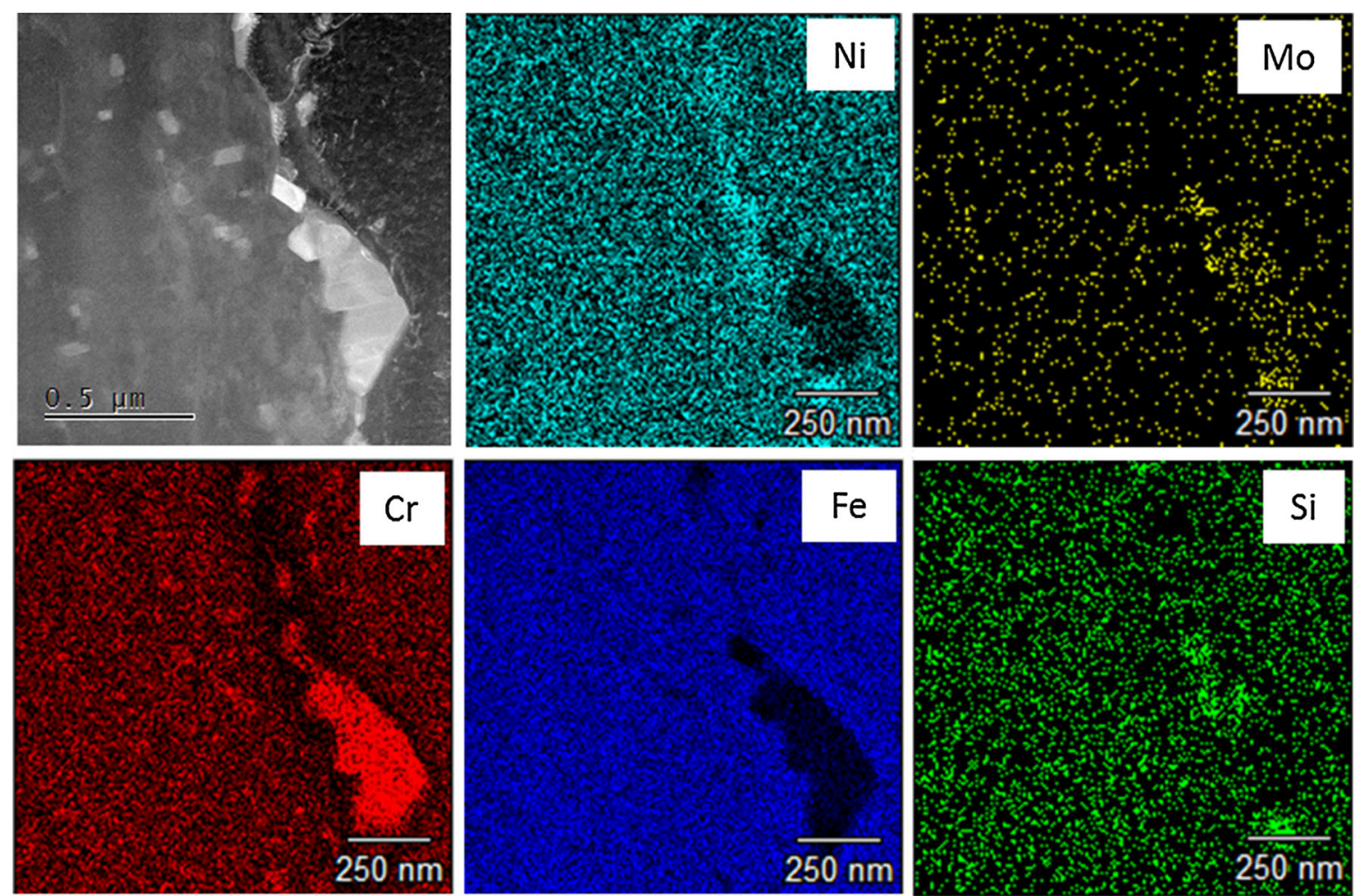

(a)
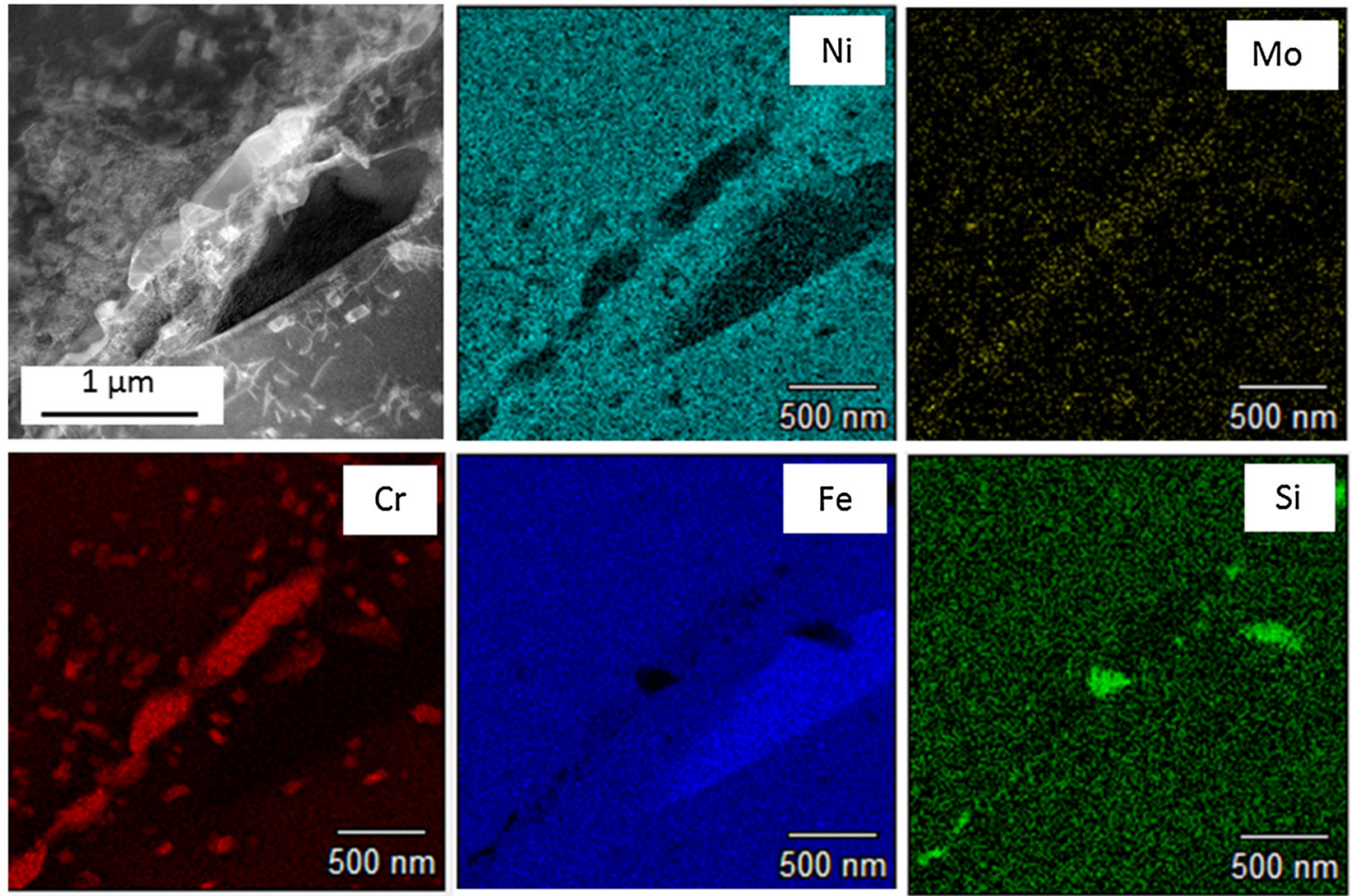

(b)

Fig. 4-EDX analysis of phases in ex-service bifurcations B and C. (a) Data from bifurcation B and (b) data from bifurcation C.

austenite-chi-phase boundaries in the header examined in this study, ${ }^{[40]}$ it is surprising that it has not been linked to modifications of the creep behavior in previous studies. $^{[24,31]}$ The $\mathrm{Cr}$ depletion around the chi-phase precipitates reduces the solute-strengthening effect in these regions, making the material weaker and further enhancing the influence of dislocation pile-ups. Based on these factors, it would be expected that chi phase would 
Table II. Composition of G Phase in the Header Interdendritic Regions and Bifurcation C

\begin{tabular}{|c|c|c|c|c|c|c|c|c|c|}
\hline \multirow[b]{2}{*}{ Specimen } & \multicolumn{9}{|c|}{ Average Measured Composition-Weight Percent } \\
\hline & $\mathrm{Si}$ & $\mathrm{S}$ & $\mathrm{P}$ & $\mathrm{Cr}$ & $\mathrm{Mn}$ & $\mathrm{Fe}$ & $\mathrm{Ni}$ & Mo & $\mathrm{Ti}$ \\
\hline $\begin{array}{l}\text { Header interdendritic } \\
\text { regions }\end{array}$ & $4.9 \pm 2$ & $1.3 \pm 2$ & $0.1 \pm 0.4$ & $20.9 \pm 12$ & $0.6 \pm 0.9$ & $20.1 \pm 15$ & $18.1 \pm 8$ & $24.2 \pm 14$ & - \\
\hline Ex-service bifurcation $\mathrm{C}$ & $47.5 \pm 5$ & - & $0.6 \pm 0.1$ & $14.1 \pm 2$ & $0.1 \pm 0.1$ & $11.6 \pm 2$ & $22 \pm 3$ & $4.5 \pm 0.5$ & $0.3 \pm 0.1$ \\
\hline
\end{tabular}

Table III. Comparison List for Phases Experimentally Observed in the Two Regions of the Ex-service AISI Type 316H Header ${ }^{[40]}$ and the Ex-service AISI Type 316H Bifurcations

\begin{tabular}{|c|c|c|c|c|c|}
\hline \multirow[b]{2}{*}{ Phases } & \multicolumn{5}{|c|}{ Material } \\
\hline & $\begin{array}{l}\text { Header Material } \\
\qquad \text { (Bulk) }\end{array}$ & $\begin{array}{c}\text { Header Material } \\
\text { (Interdendritic regions) }\end{array}$ & $\begin{array}{c}\text { Ex-service } \\
\text { Bifurcation A }\end{array}$ & $\begin{array}{c}\text { Ex-service } \\
\text { Bifurcation B }\end{array}$ & $\begin{array}{l}\text { Ex-service } \\
\text { Bifurcation C }\end{array}$ \\
\hline Austenite (bulk) & $\sqrt{ }$ & $\sqrt{ }$ & $\sqrt{ }$ & $\sqrt{ }$ & $\sqrt{ }$ \\
\hline Ferrite & $\begin{array}{c}\sqrt{ } \\
(1 \text { pct area })\end{array}$ & $\begin{array}{c}\sqrt{ } \\
\text { (3.6 pct area combined ferrite }+ \text { chi) }\end{array}$ & $\begin{array}{c}\sqrt{ } \\
(1.0 \text { pct area })\end{array}$ & $\begin{array}{c}\sqrt{ } \\
(2.3 \text { pct area })\end{array}$ & $\begin{array}{c}\sqrt{ } \\
(2.0 \text { pct area })\end{array}$ \\
\hline M23C6 & $\sqrt{ }$ & $\sqrt{ }$ & $\sqrt{ }$ & $\sqrt{1}$ & $\sqrt{ }$ \\
\hline G phase & - & $\begin{array}{c}\sqrt{ } \\
\text { (P in only } 1 / 13 \text { precipitates sampled) }\end{array}$ & - & $\begin{array}{c}\sqrt{ } \\
\text { (P enriched) }\end{array}$ & $\begin{array}{c}\sqrt{ } \\
\text { (P enriched) }\end{array}$ \\
\hline$\gamma^{\prime}$ & - & $\sqrt{[40]}$ & - & & \\
\hline Chi phase & - & $\begin{array}{c}\sqrt{ } \\
\text { (3.6 pct area combined ferrite }+ \text { chi) }\end{array}$ & - & - & - \\
\hline
\end{tabular}

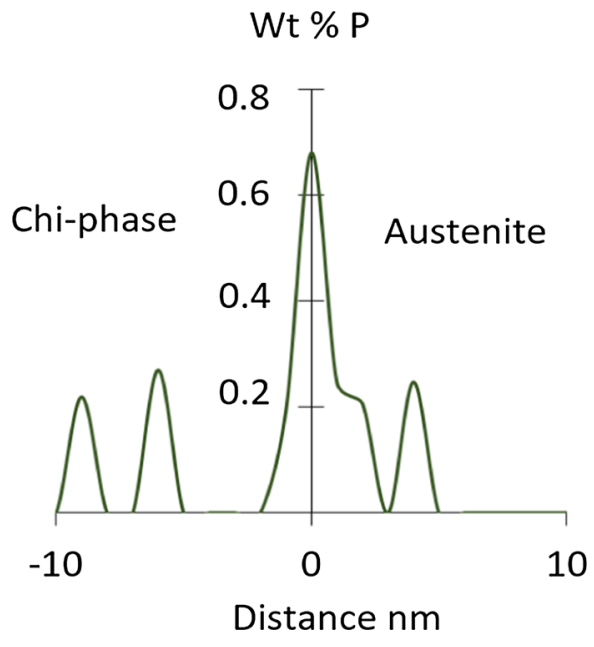

(a)

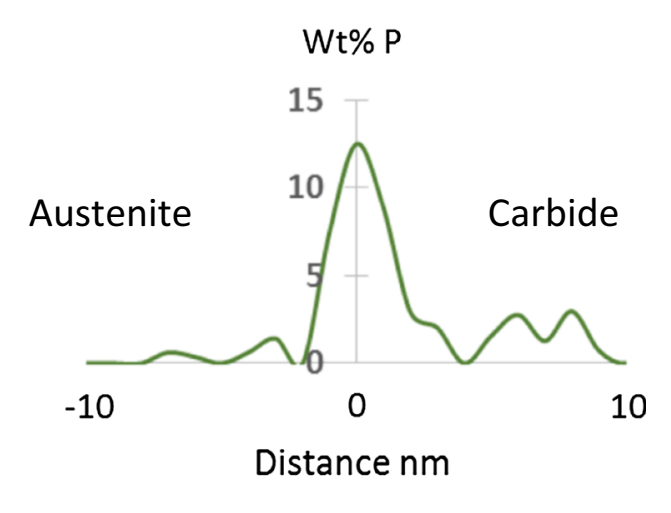

(b)

Fig. 5-Typical EDX analysis of elemental segregation at phase boundaries. (a) Elemental segregation observed in the cast header, at the austenite-chi-phase boundary and $(b)$ elemental segregation in bifurcation $\mathrm{A}$, at the austenite- $\mathrm{M}_{23} \mathrm{C}_{6}$ phase boundary. Error on these measurements is $\pm 0.1 \mathrm{wt}$ pct.

have a more significant role in creep damage accumulation than has been previously reported. ${ }^{[24,31]}$

Elemental segregation is known to modify grain boundary energies, and thus can play a role in creep cavity nucleation. Phosphorus has been observed to reduce the overall creep rate of a steel by a factor of 1000 , possibly through grain boundary strengthening ${ }^{[43-47]}$ and it also promotes intergranular corrosion and fracture. ${ }^{[44,47]}$ Most significantly phosphorus has been observed to reduce creep ductility and modify creep cavitation behavior. ${ }^{[43,45-47]}$ Studies show an enhancement of creep cavity nucleation coupled with a retardation of cavity growth. ${ }^{[45-47]}$ The retardation of cavity growth may be due to the strong phosphorus-vacancy interaction. Phosphorus appears to have an effect on the nucleation location, size, and number density of precipitated $\mathrm{M}_{23} \mathrm{C}_{6},{ }^{[43-47]}$ which may also modify cavity nucleation behavior. 


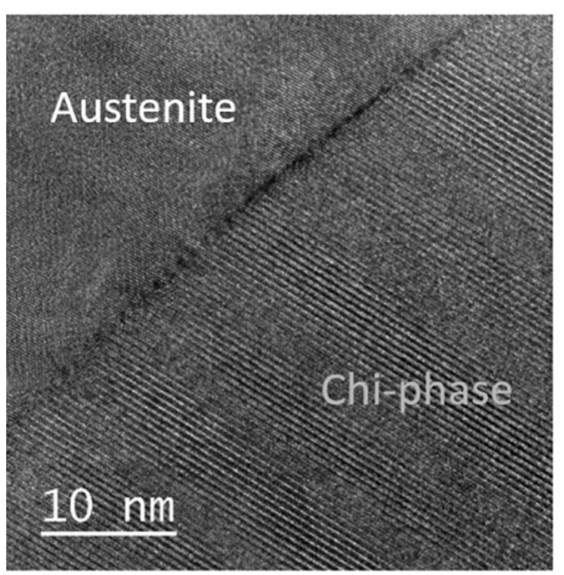

(a)

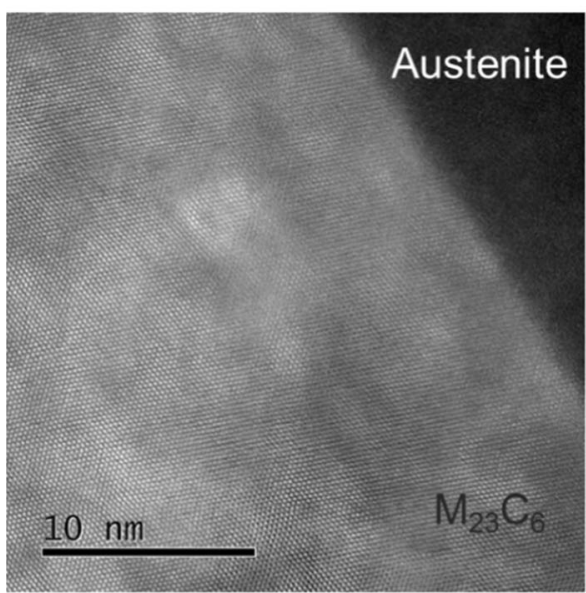

(c)

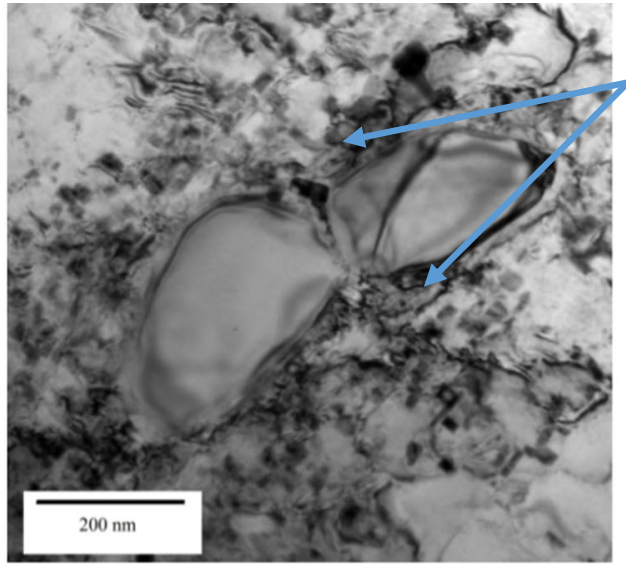

(b)

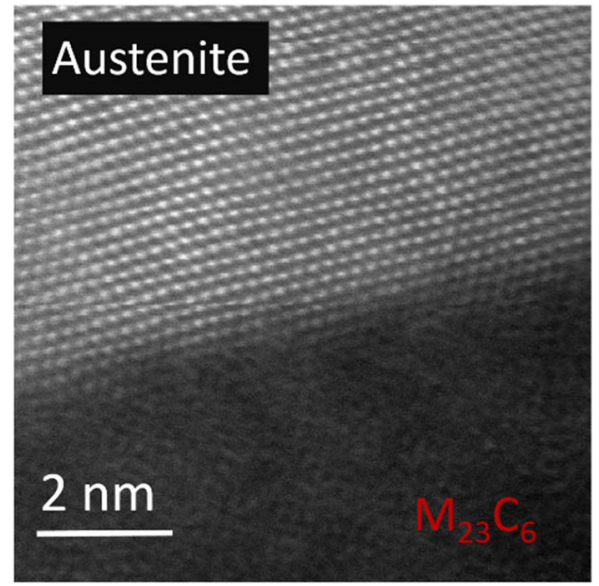

(d)

Fig. 6-Dislocation behavior of precipitates in the ex-service components. (a) Periodic dislocations at the austenite-chi-phase interface in the boiler header (reprinted with authors' permission from Ref. [40]) and (b) dislocation pile-up surrounding a chi-phase precipitate in the boiler header. $(c)$ and $(d)$ the austenite- $\mathrm{M}_{23} \mathrm{C}_{6}$ carbide interface in bifurcation $\mathrm{A}$.

The minimum stable radius of a creep cavity is a function of the surface energy of the grain boundary. Where this is associated with precipitation, both factors play a role in the number density of creep cavitation:

$$
r \geq 2 \frac{\gamma}{\sigma_{n}}
$$

where $\gamma$ is the interfacial energy of the boundary and $\sigma_{n}$ is the local steady-state tensile stress. In addition, the cavity density, $N_{a}$, is given by

$$
N_{a}=f N_{p}\left(1-\exp ^{-\kappa \varepsilon}\right),
$$

where $N_{p}$ is the precipitate density, $f$ is a function of interfacial energy, $\gamma$, and maximum principal stress, $\sigma_{1}$. $\kappa$ is the cavity interaction constant and $\varepsilon$ is strain.

Certainly, with respect to the specimens, phosphorous at the austenite-chi inter-phase boundary would be expected to enhance cavity nucleation in coordination with the increased dislocation density. In bifurcation $\mathrm{A}$, the combination of a hard secondary phase $\left(\mathrm{M}_{23} \mathrm{C}_{6}\right)$ which could lead to dislocation pile-up and the modification of grain boundary energies could combine in a similar way. Both specimens show creep cavitation and cracking, which would support this reasoning.

However, bifurcations $\mathrm{B}$ and $\mathrm{C}$ show no phosphorus segregation, and it is suggested that the increased phosphorous concentration in the $G$ phase observed in these bifurcations represents uptake by this phase and thus prevents segregation to grain boundaries. In turn, this lessens the potential for creep cavity formation at the carbide-austenite interfaces. Again, this is supported by the fact that these bifurcations contain only a low number density of creep cavities compared to the other specimens and creep cracking was not the primary source of failure, despite bifurcation $\mathrm{C}$ experiencing almost twice as long in service.

From these comparisons, it is clear that certain combinations of phases can control phosphorous segregation behavior either through sequestering it (the $\mathrm{G}$ phase in bifurcations $\mathrm{B}$ and $\mathrm{C}$ ) or promoting segregation to inter-phase boundaries $\left(\mathrm{M}_{23} \mathrm{C}_{6}\right.$ in bifurcation $\mathrm{A}$ or chi phase in the header). The phosphorous segregation is much more significant in bifurcation $\mathrm{A}$ than in the header. On a simplistic level, this could be argued to be the result of competition between the $G$ phase in the 
header and the preferential energetics of the austenite-chi inter-phase boundary. However, the $G$ phase in the header has a significantly lower concentration of $\mathrm{P}$ than in the bifurcations, which does not support this conclusion. Instead, it is proposed that the difference in segregation is due to a complex mix of factors, including differences in interfacial energy. Thus, the common assumption that all components with 'in specification' compositions are identical for creep damage forecasting and life-time assessment is inherently flawed. Certain components will be prone to different responses to failure as a result of fabrication affects and/or cast-tocast compositional variations.

\section{CONCLUSIONS}

Four AISI $316 \mathrm{H}$ components are compared. All fall within compositional design specification, and would be expected to behave similarly from the perspective of creep damage forecasting. However, differences in specific composition and fabrication route lead to different microstructures which diverge further due to variations in phase evolution behavior over time.

The fabricated boiler headers contain localized chromium-rich interdendritic regions which result in enhanced creep cavity initiation and growth in addition to a wide range of phases. Chi-phase precipitates play a crucial role in creep cavitation, showing dislocation pile-ups, localized depletion of chromium (enabling local deformation), and phosphorus segregation to the chi-austenite phase boundary. In particular, the latter will modify the energy of boundaries and reduce the stable size for cavity nucleation.

One bifurcation (A) showed a similar composition to the boiler header, but had a homogenous microstructure devoid of any identifiable interdendritic regions. This bifurcation exhibited limited secondary phase evolution despite prolonged service (160,000 hours). Creep cavities are associated with $\mathrm{M}_{23} \mathrm{C}_{6}$ precipitates, which exhibit phosphorus segregation to the $\mathrm{M}_{23} \mathrm{C}_{6}$ carbide-austenite phase boundary. The remaining two bifurcations (B and C) contained G-phase precipitates which appeared to partition the $\mathrm{P}$ and prevent segregation to boundaries.

As a consequence of the above, the role of fabrication and cast-to-cast variation need to be accommodated for accurate component creep life prediction due to their potential to significantly alter the time $(65 \mathrm{k} v s 300 \mathrm{k}$ hours in this study) and pathway-to-failure. Due to the effect of localized microstructure modifying the distribution of elements, simple CALPHAD predictions may not be suitable for this purpose.

\section{ACKNOWLEDGMENTS}

The authors would like to thank EDF Energy Limited for financing this work, provision of the sample materials. The views expressed are those of the authors and not EDF Energy Limited. Ana Martinez-Ubeda would like to thank Marc Chevalier (EDF Energy Limited) for helpful discussions. The authors acknowledge financial support from the EPSRC PROMINENT (EP/ I003207/1) consortium for funding this research, with thanks to EPSRC for funding the Jeol-ARM 200F EPSRC South of England Analytical Electron Microscope located at Oxford University (EP/K040375/1). PEJ Flewitt is grateful to Wolfson College, Oxford for facilitating the collaboration and acknowledges the many helpful and interesting discussions with Dr Bo Chen, now of Coventry University, UK.

\section{CONFLICT OF INTEREST}

The authors declare that they have no conflict of interest.

\section{OPEN ACCESS}

This article is distributed under the terms of the Creative Commons Attribution 4.0 International License (http://creativecommons.org/licenses/by/4.0/), which permits unrestricted use, distribution, and reproduction in any medium, provided you give appropriate credit to the original author(s) and the source, provide a link to the Creative Commons license, and indicate if changes were made.

\section{REFERENCES}

1. K.L. Murty and I. Charit: J. Nucl. Mater., 2008, vol. 383 (1-2), pp. 189-95.

2. K.H. Lo, C.H. Shek, and J.K.L. Lai: Mater. Sci. Eng. R Reports, 2009, vol. 65 (4-6), pp. 39-104.

3. G. Lothongkum, E. Viyanit, and P. Bhandhubanyong: J. Mater. Process. Technol., 2001, vol. 110, pp. 233-38.

4. V.P. Kujanpaa: Weld. J., 1983, vol. 62 (2), p. 45.

5. B. Weiss and R. Strickler: Metall. Trans., 1972, vol. 3 (4), pp. 851-66.

6. A. Joseph, S.K. Rai, T. Jayakumar, and N. Murugan: Int. J. Press. Vessel. Pip., 2005, vol. 82, pp. 700-05.

7. B. Chen, P.E.J. Flewitt, and D.J. Smith: Mater. Sci. Eng. A, 2010, vol. 527 (27-28), pp. 7387-99.

8. D.G. Morris and D.R. Harries: Met. Sci., 1978, vol. 12 (11), pp. 532-41.

9. S.A. David and J.M. Vitek: Weld. J., 1985, vol. 65 (4), pp. 106-11.

10. V. Mazurovsky, M. Zinigrad, L. Leontiev and V. Lisin: Carbide formation during crystallization upon welding. Third International Conference on Mathematical Modeling and Computer Modeling and Computer Simulation of Materials Technologies MMT, 2004.

11. J.W. Elmer, S.M. Allen, and T.W. Eagar: Metall. Trans. A, 1989 , vol. $20(10)$, pp. $2117-31$

12. O. Hammar and U. Svensson, Influence of steel composition on segregation and microstructure during solidification of austenitic stainless steels. Solidification and Casting of Metals $\backslash$ Proc. Conf $\backslash$ Sheffield, England, 1977, pp 401-10.

13. G.L. Leone and W.H. Kerr: Weld. J., 1982, vol. 61, pp. 13-21

14. T. Schubert, W. Löser, S. Schinnerling, and I. Bächer: Mater. Sci. Technol., 1995, vol. 11, pp. 181-85.

15. H.U. Hong, B.S. Rho, and S.W. Nam: Int. J. Fatigue, 2002, vol. 24, pp. 1063-70.

16. H.C. Vacher and C.J. Bechtoldt: J. Res. Natl. Bur. Stand., 1954, vol. 53 (2), pp. 67-76. 
17. B.S. Rho, H.U. Hong, and S.W. Nam: Int. J. Fatigue, 2000, vol. 22 , pp. $683-90$.

18. B.S. Rho, H.U. Hong, and W.S. Nam: Scr. Mater., 1998, vol. 39, pp. $1407-12$.

19. D.L. Olson: Weld. J., 1985, vol. 64 (10), pp. 281-95.

20. K. Easterling: Introduction to the Physical Metallurgy of Welding, Butterworths, London, 1985, pp. 83-33.

21. D.M. Escriba, E. Materna-Morris, R.L. Plaut, and A.F. Padilha: Mater. Charact., 2009, vol. 60 (11), pp. 1214-19.

22. A.F. Padilha and P.R. Rios: ISIJ Int., 2002, vol. 42 (4), pp. 325-27.

23. T. Sourmail: Mater. Sci. Technol., 2001, vol. 17 (1), pp. 1-14.

24. P. Shankar, H. Shaikh, S. Sivakumar, S. Venugopal D. Sundararaman, and H.S. Khatak: J. Nucl. Mater., 1999, vol. 264 , pp. $29-34$.

25. A.C. Stauffer, D.A. Koss, and J.B. McKirgan: Metall. Mater. Trans. A, 2004, vol. 35A, pp. 1317-24.

26. T.P.S. Gill, M. Vijayalakshmi, J.B. Gnanamoorthy, and K.A. Padmanabhan: Weld. J. Suppl., 1986, vol. 65, pp. 122-28.

27. J. Michalska and M. Sozanska: Mater. Charact., 2006, vol. 56, pp. $355-62$.

28. S.K. Ghosh and S. Mondal: Mater. Charact., 2008, vol. 59, pp. $1776-83$.

29. I. Calliari, M. Zanesco, and E. Ramous: J. Mater. Sci., 2006, vol. 41, pp. 7643-49.

30. E. Ruedl and T. Sasaki: J. Nucl. Mater., 1984, vol. 122, pp. 794-98.

31. B.A. Senior: J. Mater. Sci., 1990, vol. 25, pp. 45-53.

32. F.X. Spiegel, D. Bardos, and P.A. Beck: Trans. Metall. Soc. AIME, 1963, vol. 227, pp. 575-79.
33. I. Shuro, H.H. Kuo, T. Sasaki, K. Hono, Y. Todaka, and M. Umemoto: Mater. Sci. Eng. A, 2012, vol. 552, pp. 194-98.

34. M. Vrinat, R. Cozar, and Y. Meyzaud: Scr. Metall., 1986, vol. 20, pp. 1101-06.

35. D.J. Powell, R. Pilkington, and D.A. Miller: Acta Metall., 1988, vol. 36 (3), pp. 713-24.

36. B. Piekarski: Mater. Charact., 2001, vol. 47, pp. 181-86.

37. R.C. Ecob, R.C. Lobb, and V.L. Kohler: J. Mater. Sci., 1987, vol. 22 , pp. 2867-80.

38. J.M. Vitek, S.A. David, D.J. Alexander, J.R. Keiser, and R.K. Nanstad: Acta Metall. Mater., 1991, vol. 39, pp. 503-16.

39. J.E. Brown and G.D.W. Smith: Surf. Sci., 1991, vol. 246, pp. 285-91.

40. A.D. Warren, I.J. Griffiths, and P.E.J. Flewitt: J. Mater. Sci., 2018, vol. 53 (8), pp. 6183-97.

41. K. William, D.J. Dyson, and S.R. Keown: Interpretation of electron diffraction patterns, Hilger and Wats, London, 1971, p. 210.

42. Y. Yang and J.T. Busby: J. Nucl. Mater., 2014, vol. 448 (1-3), pp. 282-93.

43. G. Sasikala, S.L. Mannan, M.D. Mathew, and K.B. Rao: Metall. Mater. Trans. A, 2000, vol. 31A, pp. 1175-85.

44. C. Younes, P.E.J. Flewitt, P.J. Heard, and R.K. Wild: Metall. Mater. Trans. A, 2000, vol. 31A, pp. 615-28.

45. S.P. Hong, J.H. Nam, and S.W. Choi: J. Mater. Sci., 1986, vol. 21, pp. 3966-76.

46. M. Burton: Annu. Rev. Phys. Chem., 1952, vol. 1, pp. 113-32.

47. B. Chen; Effects of thermo mechanical history on creep damage in 316H austenitic steel, PhD thesis University of Bristol, 2011. 